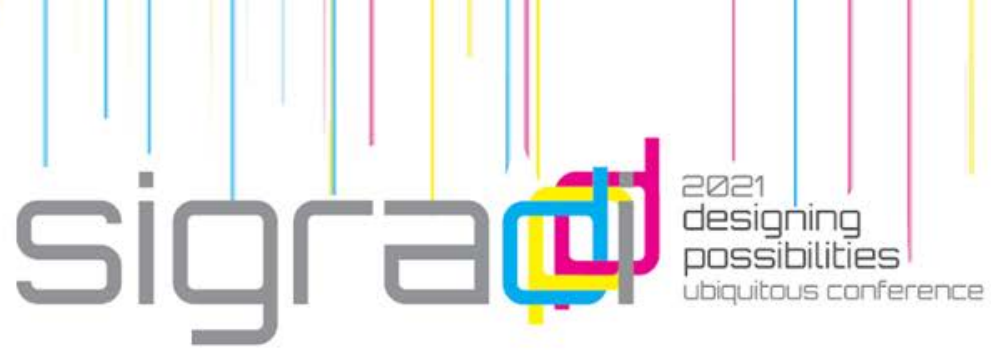

\title{
A Data-Driven Participatory Decision Model Proposal in the Context of Urban Vibrancy
}

\author{
Gülce Kırdar $^{1}$, Gülen Çağdaş² \\ ${ }^{1}$ Istanbul Technical University, Graduate School, Department of Informatics, \\ Architectural Design Computing Program, Istanbul, Turkey \\ kirdarg@itu.edu.tr \\ ${ }^{2}$ Istanbul Technical University, Faculty of Architecture, Department of Architecture, \\ Istanbul, Turkey \\ cagdas@itu.edu.tr
}

\begin{abstract}
This paper focuses on the vibrancy of urban environments in the context of liveability. The objective is to explore the interrelationships of activity determinants what attracts visitors to support vibrancy decisions. The research questions how to uncover the relationships among vibrancy parameters and how to utilize the relation network for decision support. We utilize Bayesian Belief Network (BBN) for relational analysis and support with expert participation for an efficient decision-making. In this way, we expect to develop a causal by calibrating the data-driven BBN network. The results show that the user density has direct relationship with public open space, place rate, activity diversity, landmarks' visitation rate cultural attributes, and accessibility; indirect relationship with time diversity, activity diversity and density. The results support the arguments on the importance of activity diversity in space and time, and intense urban pattern within the attractiveness public spaces for urbanity.
\end{abstract}

Keywords: Big data, Data-driven analysis, Urban vibrancy, Liveability, Participatory approach.

\section{Introduction}

Liveability is an urban policy that targets to improve the spatial, social and economic conditions of the citizens. We recognize the multidimensionality of liveability, and approach it from the aspect of urban vibrancy with the questions of which factors attracts visitor and increase the user density. The aim is to conduct a knowledge discovery process through the physical and digital urban data layers with the support of expert participation to understand urban 
vibrancy. This paper positions itself at the intersection of data-driven and participatory approaches.

This paper starts with the literature review on vibrancy measures, continues with the introduction of BBN and its use in urban studies. In the methodology, we employ the Bayesian inference for knowledge discovery of big data, and support it with survey for better evaluation of urban vibrancy. In the survey, we asked the participants, who are dealing with urban studies, to compare vibrancy parameters in pairs according to causality or correlation. As a result, we demonstrate to what extend the Bayesian Belief Network reveals the causal relationships based on the survey results. We termed the representation of causal relationships as causal network. The causal network will be used to monitor the consequences of vibrancy decisions on neighborhoods.

\subsection{Urban Vibrancy for Liveable Environments}

Liveability can be described as an umbrella term that covers all of the spatial and socio-economic factors for a place to be successful. Liveable public spaces should be walkable, accessible, affordable, green, healthy, attractive, vibrant, friendly, mixed-use, and human-scaled built environments, within high quality of life of citizens (Ling and Yuen, 2009). As Carmona (2019) states, a successful place is a quality place where the economic, environmental social and cultural value is satisfactory. In the scope of the liveability, we focus on the urban vitality that delivers economic and social value of the place, as the evidences in Carmona's study (2019) find out. Montgomery (1998) and Jacobs (1961) also favor the active urbanity as a proxy of a successful neighborhood. This paper takes the activity principles (Montgomery, 1998) and good neighborhood indicators (Jacobs, 1961) within the evidences of the urban vitality (Carmona, 2019) as a reference to determine the parameters of urban vibrancy. Based on the references we determine active people density as indicator, and activities' spatial and temporal diversity, activity places' attractiveness, visitor accessibility to activities, public open space, cultural landmarks' density and attractiveness (based on visitation rate) as the determinants of urban vibrancy.

Montgomery (1998) emphasizes activity as the prerequisite of urbanity, and the active pedestrian density as a proxy of urbanity, which is defined urban vibrancy in this study. According to Jacobs (1961), successfully mix-used urban quarters tend to be more economically viable, socially balanced, attractive and safer. The density, diversity, distribution of the activities within the temporal diversity are the necessities of successful mix-use (Grant, 2007). The temporal diversity concept is affected from the phenomenon of 24-hour city, that aims the dispersion of urban functions' operating time both daily and weekly (Dantzig and Saaty, 1973). Accessibility complements activities; it measures the ease to reach activities considering the amount, features and spatial distribution of activities (Handy and Niemeier, 1997). Public open spaces (POS) are the essence of everyday life of the public by fostering user activities, perceptions 
and experiences of the place (Carmona, 2014). Lastly, the urban heritage is an complementary of a successful public life with POS. Urban heritage improves both sense of place for urbanities and attractiveness for visitors. We accept the $\mathrm{CH}$ landmarks as the representations of urban heritage. Landmarks are the reference point for the observer of the city (Lynch, 1960). Cultural heritage $(\mathrm{CH})$ landmarks are the cultural monuments or buildings which have cultural and historical significance, so the cultural reference point of the city. Montgomery (1998) and Jacobs (1961) also put an emphasize on people attractors for urbanity. In this study, we assume that the user ratings of the place and visitation rate of the cultural landmarks indicate to what extend the activity place and cultural landmark is attractive.

Istanbul Historical Peninsula is the testbed for this study. The Historical Peninsula district shows rich variety in activities, building pattern, within cultural attributes, socio-economic structure (Turgut and Özden, 2005). The cultural heritage sites in the peninsula are ranked in UNESCO Heritage List due to the outstanding cultural values from different civilizations. However, the Historical Peninsula encounters use-derived problems that influence urban liveability negatively. These difficulties are mainly derived from the imbalances of visitor density that varies in time and place; the deficiencies in quality of public open space and public amenities; the physical degradation of the cultural assets; and lack of place attachment and decay in social fabric (Istanbul Metropolitan Municipality [IMM] Department of Cultural Assets Conservation, 2017; UNESCO Turkey National Commission, 2009). The big scaled transportation and urban transformation projects pose threats on the urban services and the unique character of the site (UNESCO, 2006). The addition of the urban transformation pressure on the user-derived challenges increases the risk of the site of being an urban deprivation area (Turgut and Özden, 2005), and excluding from the UNESCO Heritage List (World Heritage Center [WHC], 2010). The potentials and problems in the area encourage decision-makers to revitalize the district. We select the Istanbul Historic Peninsula District due to the abundancy of the academic study and planning decisions about the revitalization of the site. In this paper, we aim to offer a data-driven decision support model to evaluate the planning decisions related with urban vibrancy.

We examine the vibrancy conditions in Istanbul Historic Peninsula District through crowdsourcing the LBSN data to support decisions about active public realm. As defined in Springler dictionary (Lee and Yee, 2014), Location Based Social Network (LBSN) data is data from locative technologies which range from the websites, platforms, applications, to mobile and online services. LBSN has been used interchangeably with geosocial data, geospatial data and user generated content. We collect big amount of geospatial data (i.e., LBSN data) and analyze to retrieve useful information with big data approach. Big data concept implies the use high volume of data with high velocity and variety, which are $3 \mathrm{~V}$ characteristics to improve decision making and gain insight (Laney, 2001). Urban scholars analyze the user-generated content (UGC) data to generate useful knowledge about cities' functioning and liveability. 
Crowdsourcing big urban data to support urban decisions has become an urban research hotspot.

In the urban literature, UGC has been widely used to reveal the attraction points (Garcia-Palomares et al., 2015), and monitor user movement pattern (Girardin et al., 2008). Big data analytics implements data-driven approach for knowledge discovery, such as data mining techniques, statistical analysis, machine learning and artificial intelligence and Bayesian inferences in urban informatics. We adopt big data approach to analyze multiple LBSN sources and implement Bayesian inferences for data analysis, which is explained above.

\subsection{Bayesian Belief Network}

Bayesian Belief Network (BBN) is probabilistic models in the form of directed acyclic graphs. The directed acyclic diagrams describe the distribution of conditional probability for each node. BBN represents a compact model through conditional probabilities with the purpose of reasoning under uncertainty (HUGIN Expert, 2020). BBN has the capability to explore a meaningful relationship network between large set of variables by detecting all direct and indirect relations simultaneously (Kemperman and Timmermans, 2014). BBN also presents the easiness in calibration and validation of the network with the new information update, and therefore, fits to adaptive management concepts (McCloskey et al., 2011). Bayesian Belief Network can be constructed with two ways: the automated learning algorithms and expert knowledge. The learning algorithms relies on conditional independence $(\mathrm{Cl})$ and search-and-scoring (Lee and Lee, 2012). The search-and-scoring based algorithm selects the highest scoring relationship pair whose correlations are calculated by statistical tests for BBN formation; while $\mathrm{Cl}$-based learning algorithm measures the conditional independencies of nodes (variables) (Lee and Lee, 2012). The NPC algorithm allows expert to resolve the inconsistencies by selecting the relationship pair among the alternatives or decide its direction (HUGIN Expert, 2020).

In the urban literature, the BBN has been used to reveal the relationship between determinants of mobility satisfaction (Yanık et al., 2017), social interaction in living environments (Kemperman and Timmermans, 2014), and neighborhoods popularity (Ardıc, Kırdar, Lima, 2020). BBN also allows to expert participation to assess alternative scenarios (McCloskey et al., 2011), and develop a causal BBN model (Yanık et al., 2017). Among different BBN programs the researchers employ HUGIN, which is an acronym of the Handling Uncertainty in General Inference Networks. The manual and automated construction (using database) of Bayesian models, and data conflict analysis are the advantages of the program to be chosen (Madsen et al., 2005). Next section dwells on the construction of BBN with learning algorithms using HUGIN tool. 


$$
\begin{aligned}
& \mathrm{D}_{\mathrm{i}}=\mathrm{D} / \mathrm{D}_{\max } \\
& \mathrm{D}=1-\sum \frac{\mathrm{n}(\mathrm{n}-1)}{\mathrm{N}\left(\mathrm{N}_{!}\right)} \\
& \mathrm{H}=-\sum_{\mathrm{i}=1}^{\mathrm{p}} \mathrm{p}_{\mathrm{i}} \operatorname{lnp}_{\mathrm{i}} E_{h}=H / H_{\max }
\end{aligned}
$$

To measure time diversity, the paper takes the time-span classification (Tan and Klassen, 2007) as a baseline referring to Dantzig and Saaty (1973). We categorize the operational hours of the amenities according to the time-span classification. We define temporal trend as the average daily working hours of the amenities in the neighborhood. The conventional time span denotes that places' average daily working hour is equal and less than 12 hours. The extended time span corresponds to the average daily working hours between 12 and 15 hours, while the extended plus means the 15 or more average daily working hours. Accordingly, we calculate the temporal trend of each neighborhood and label as conventional, extended or extended plus time span.

The types of accessibility measures as distance, topological, place, and individual measures, as Handy and Niemeier (1997) describe. This study deals with a place-based accessibility measuring, cumulative opportunities index. The cumulative opportunity index counts the number of opportunities that can be reached within a determined travel time or distance, whose equation is displayed in Equation 4 (Handy and Niemeier, 1997). The focus is on the potential destination numbers to be accessed in the given travel criteria (time or distance). The accessibility has been calculated from bus stations to activity places (cumulative opportunities). Regarding the proximity and abundance of transportation opportunities in the site, the common 5-minutes walking distance has been descended into 3 minutes (200-meter radius). The researchers apply several data sources to get the transportation points: Google Places API (2021) (taxi stands, and parking plots), IBB Open Data (2021) (bus stations), OSM provider via OSM Quick Plugin (transit stations). In case of conflict, the study prioritizes IBB data, then Google Places API and finally OSM. This prioritization stems from the reliability of the data sources; Open IBB Data Platform presents official data, while other resources take advantage of crowdsourcing.

$$
A_{i}=\sum_{i} a_{i} f\left(t_{i j}\right)
$$

The research measures the visitation rate to cultural landmarks using referring to Woods' study (2013). Wood and other researchers (2013) develop an alternative visitation rate at recreational use, based on the number of userdays of photographs, taken from Flickr. This method stands for 'photo-userdays' (PUD) measure, and used to predict the number of visits in the recreation area. The user-days are the total number of days, when each user takes photographs in the specified location (Wood et al., 2013). To calculate this index, the number of the unique combinations of the users and locations has been counted for each day and then averaged to years to find the mean of photo-user-days for place. Wood and other researchers' (2013) studies argue 
that there is a reliable statistical relationship between the visitation statistics and Flickr user-days. This research applies this method to measure the visitation rate to cultural landmarks. The information about cultural landmarks has been taken from the Google Places API, the Master Development Plan (Istanbul Metropolitan Municipality [IMM] Urban Authority, 2011), and Historic Areas of Istanbul Site Directorate (2021).

To measure the user density, we benefit from visitor check-in number data scrapped from Foursquare. Swarm, accompanying app of Foursquare used to make check-ins, lists the popular points of interests (POI) in the surroundings. The app determines POls according to the visitor density. We scrapped the visitor numbers from Swarm apps in POIs. The POIs involve cultural, dining, leisure, accommodation, shopping and institutional activity places. We utilize the fishnet-based density clustering method, as a spatial statistic method. We create $200 \times 200 \mathrm{~m}$ hexagons as a fishnet, then sum the total visitor population in each POIs inside the hexagon grid.

Finally, data about public open spaces (POS) has been collected from the Master Development Plans (IMM Urban Authority, 2011), OSM provider (via OSM quick plugin), open data platform (Open IBB, 2021), and Google Places API (2021). Among the collected data sources, Open IBB data platform has the first priority, Google Places results and OSM providers the second, and Master Development Plans (IMM Urban Authority, 2011) has the third priority because this data source is not up to date. Figure 1 displays the flowchart of calculation activity diversity, visitation rate (PUD), and user density respectively.

\subsection{Urban Vibrancy Analysis with BBN}

This research benefits the Bayesian Belief Network's reasoning ability (BBN) to uncover the relationship network between the vibrancy measures. We apply for a network learning algorithm (Kemperman and Timmermans, 2014) to construct a Bayesian network. Among the network learning algorithms (mentioned in Section 1.2), we employ Necessary Path Condition (NPC) algorithm, which is a subclass of conditional independence-based learning algorithms. We build a Bayesian network from the database of urban vibrancy measures. The steps of BBN construction through database are as follows:

- Discretize data manually the measurement of dataset from ratio to interval level with two classes according to the mean of dataset;

- Establish a semi-automated BBN network with NPC learning algorithm;

- Conduct Kendall's tau bivariate correlation test as statistical analysis to resolve the ambiguous zone in the construction of $\mathrm{BBN}$;

- Select the applicable relationship based on bivariate correlation results (for multiple solutions, select the one with bigger correlation coefficient) to eliminate expert bias.

After the construction of BBN network (Figure 1), the survey benefits to clarify the causal relationships in the BBN network. In this survey, the participants assess the correlation or causality of the relationship pairs. This 


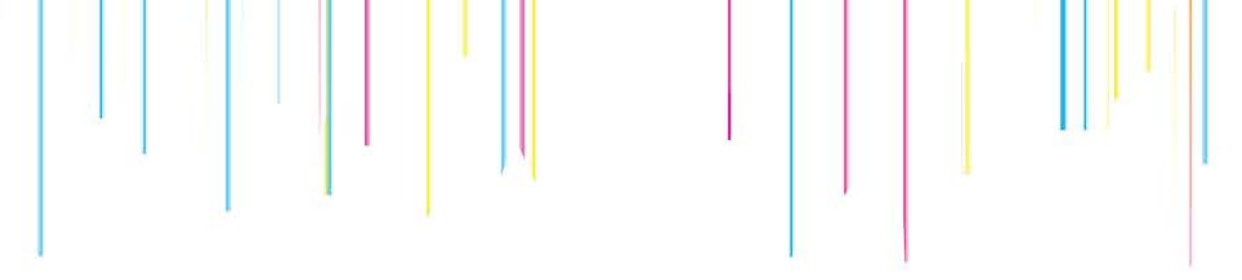

user density of being low increases by $8 \%$. Based on the updates in CPT tables, the visitation rate to landmarks has the strongest effect on user density with $24 \%$ change, while the cultural heritage the second with $17 \%$ change, place rate and activity diversity moderate effect $15 \%$ and $12 \%$ change and the accessibility and public open spaces (POS) have the weakest effect on user density with $9 \%$ change in user density probability.

According to BBN analysis results, we deduce that increasing the attraction of cultural landmarks are crucial to attract visitors. The public open spaces should be also increased as the visitors cluster around the POS. Diversifying dense of activity with equally distributed and spreading the operating time of activities also act important role for user density. The results support the importance of spreading the activities to different daytime and places, creating intense urban pattern saturated with dense and diverse activities, and the quality and attractiveness of the public open spaces for successful urban quarters as Jacobs (1961) and Montgomery (1998) emphasize.

Table 1. The conditional probability table with updated probabilities (in \%).

\begin{tabular}{|c|c|c|c|c|}
\hline \multirow{2}{*}{ Variables } & & \multicolumn{3}{|c|}{ Visitor density in POls } \\
\hline & & initial & low & high \\
\hline \multirow{2}{*}{$\begin{array}{l}\text { PUD CH } \\
\text { landmark }\end{array}$} & Low & 56.63 & 63.82 & 36.18 \\
\hline & High & 46.37 & 26.91 & 70.08 \\
\hline \multirow[t]{2}{*}{$\mathrm{CH}$ density } & Low & 56.63 & 66.57 & 34.43 \\
\hline & High & 46.37 & 36.08 & 63.91 \\
\hline \multirow[t]{2}{*}{ Accessibility } & Low & 56.63 & 69.51 & 30.49 \\
\hline & High & 46.37 & 44.52 & 55.48 \\
\hline \multirow{2}{*}{$\begin{array}{l}\text { Activity } \\
\text { diversity }\end{array}$} & Low & 56.63 & 68.83 & 31.17 \\
\hline & High & 46.37 & 49.67 & 50.33 \\
\hline \multirow{2}{*}{$\begin{array}{l}\text { Place rate } \\
\text { (likeability) }\end{array}$} & Low & 56.63 & 71.04 & 28.96 \\
\hline & High & 46.37 & 49.1 & 50.9 \\
\hline \multirow{2}{*}{$\begin{array}{l}\text { Public Open } \\
\text { Space }\end{array}$} & Low & 56.63 & 65.38 & 34.62 \\
\hline & High & 46.37 & 41.74 & 56.26 \\
\hline
\end{tabular}

We conduct a survey study to assess the causality and correlation in the relationship between variables. The survey was implemented to a small sample consisting of six researchers who have engaged in urban studies in their master $(28.57 \%)$ or doctorate education $(71.43 \%)$. In the survey, we request the participants to compare the causality and correlation in a pairwise relationship matrix. Figure 3 demonstrates the results of participants' evaluation. The percentage of being causal $(\mathrm{N})$ or correlational $(\mathrm{K})$ relationship is written in the cells, based on participants selection. Regarding the majority rate of the responses, the relational network has been assessed according to causality and correlation. Figure 4 describes the causal map of urban vibrancy variables. 


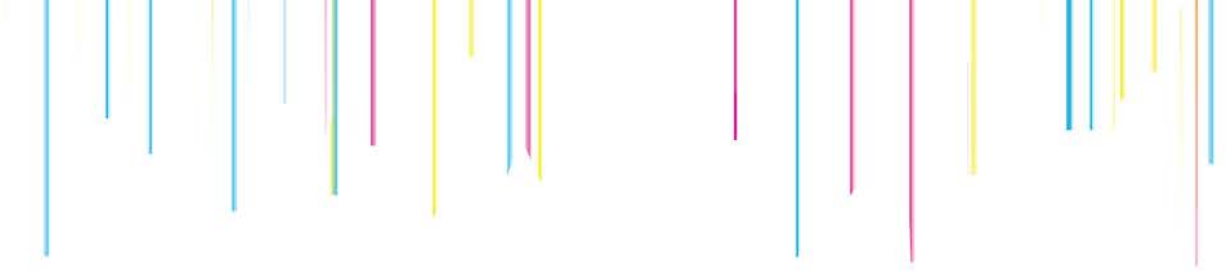

This evaluation answers the question of to what extend the Bayesian Network indicates the causal relationships. Accordingly, $85 \%$ of the BBN associations have been found causal and $15 \%$ are correlational. We expect that the causal map supports urban decision-makers to vitalize neighborhoods in cultural site.

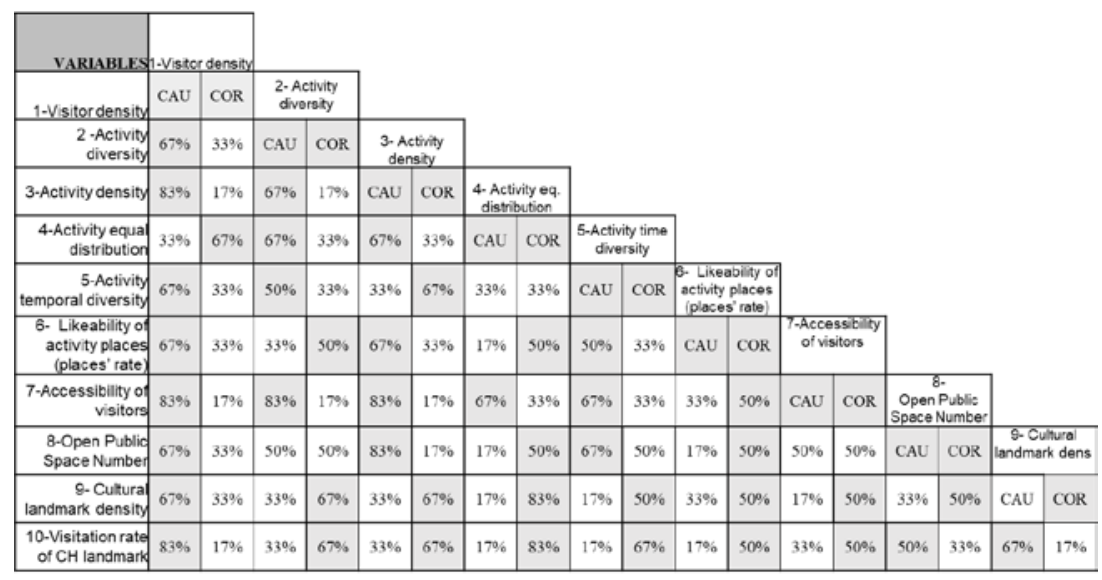

Figure 3. The pairwise relationship comparison table results (source: Authors).

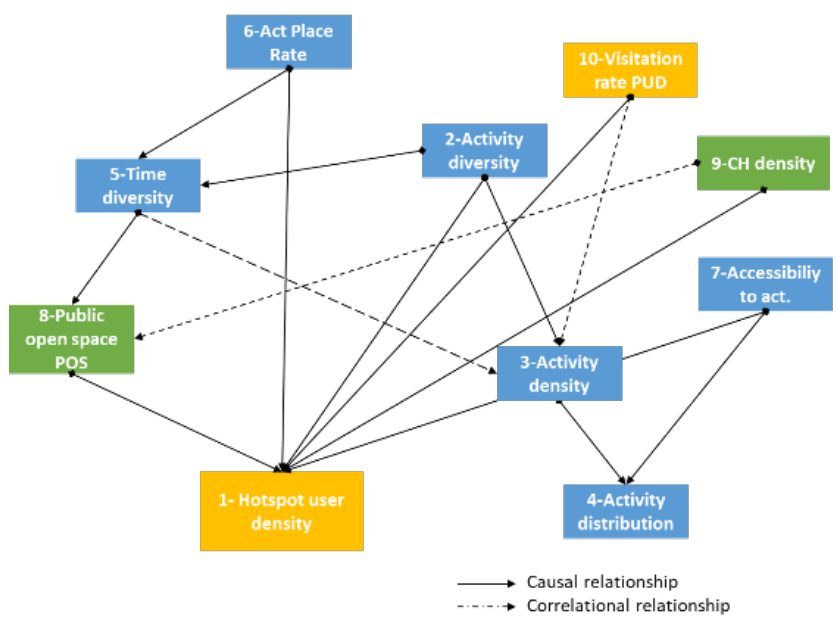

Figure 4. The Bayesian Network (source: Authors).

\section{Conclusion}

In this study we conduct exploratory data analysis supported by participation to support urban vibrancy decisions. We collect the evidences about what makes a place more vibrant to determine the gauges of vibrancy. We apply BBN analysis to reveal the relationship network between the measures, and then specify the causal relationships based on the expert participation. The results 


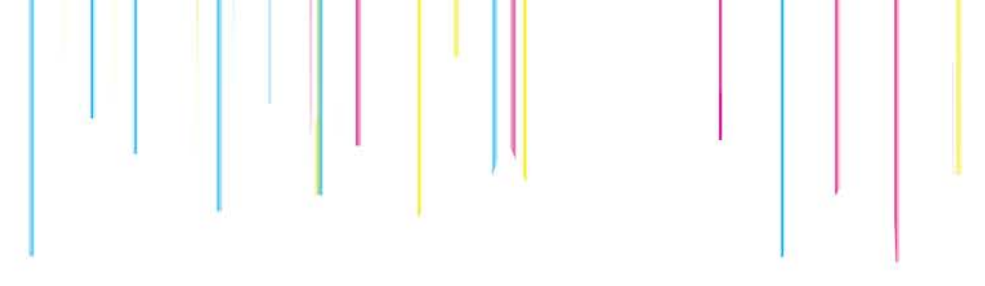

Carmona, M. (2019). Place value: Place quality and its impact on health, social, economic and environmental outcomes. Journal of Urban Design, 24(1), 1-48. https://doi.org/10.1080/13574809.2018.1472523

Dantzig, G. B., Saaty, T.L. (1973). Compact city: A plan for a liveable urban environment. W. H. Freeman and Company.

Garcia-Palomares, J.C., Gutierrez, J., Minguez, C. (2015). Identification of tourist hot spots based on social networks: A comparative analysis on European metropolises using photo-sharing services and GIS. Applied Geography, 63(2015), 408-417. http://dx.doi.org/10.1016/j.apgeog.2015.08.002

Girardin, F., Calabrese, F., Fiore, F. D., Ratti, C., \& Blat, J. (2008). Digital footprinting: Uncovering tourists with user-generated content. IEEE Pervasive Computing, 7(4), 36-43. https://doi.org/10.1109/MPRV.2008.71

Google Places API. (2021). https://developers.google.com/places/web-service/overview

Grant, J. (2007). Encouraging mixed use in practice. In G. J. Knaap, A. Haccou, K.L. Clifton, W. Frece (Eds.), Incentives, Regulations and Plans: The Role of States and Nation-States in Smart Growth Planning (pp. 57-76). Edward Elgar Publishing. https://doi.org/10.4337/9781847204325.00011

Handy, S. L., \& Niemeier, D. A. (1997). Measuring accessibility: An exploration of issues and alternatives. Environment and Planning $A$, 29(7), 1175-1194. https://doi.org/10.1068/a291175

Historic Area of Istanbul Site Directorate. (2021). Retrieved July 20, 2021, from http://www.alanbaskanligi.gov.tr/

HUGIN Expert, (2020). HUGIN GUI Manual. Retrieved July 27, 2021, from http://download.hugin.com/webdocs/manuals/8.9/downloads/545b768771d6db8e4 2d51ecafa712c7b/HUGINGUI.pdf

Istanbul Metropolitan Municipality (IMM). (2020). IMM Open Data. https://data.ibb.gov.tr/en/

Istanbul Metropolitan Municipality (IMM) Urban Planning Authority. (2011). Conservation oriented master development plans.

Istanbul Metropolitan Municipality Department of Cultural Assets Conservation. (2017). Istanbul tarihi ve kültürel miras alanlarında koruma stratejileri [The conservation strategies in Istanbul historical and cultural heritage sites].

Jacobs, J. (1961). The death and life of great American cities (third ed.). Random House.

Kemperman, A. Timmermans, H. (2014). Green spaces in the direct living environment and social contacts of the aging population. Landscape and Urban Planning, 129(2014), 44-54. https://doi.org/10.1016/j.landurbplan.2014.05.003

Laney, D. (February, 2001). 3D data management: Controlling data volume, velocity, and variety. Technical report, META Group. http://blogs.gartner.com/douglaney/files/2012/01/ad949-3D-Data-Management-Controlling-Data-Volume-

Velocity-and-Variety.pdf 
Lee, W.C., Ye M. (2014). Location-Based Social Networks. In R. Alhajj, J. Rokne (Eds.), Encyclopedia of Social Network Analysis and Mining. Springer. https://doi.org/10.1007/978-1-4614-6170-8_319

Lee, S., Lee, K.C. (2012). Context-prediction performance by a dynamic Bayesian network: Emphasis on location prediction in ubiquitous decision support environment. Expert Systems with Applications, 39(5), 4908-4914. https://doi.org/10.1016/j.eswa.2011.10.026

Ling, O.G., Yuen, B. (2009). World cities: Achieving liveability and vibrancy. World Scientific Publishing.

Lynch, K. (1960). The image of the city (second ed.). MIT Press.

Madsen, A. L., Jensen, F., Kjaerulff, U.B., Lang, M. (2005). The HUGIN tool for probabilistic graphical models. International Journal on Artificial Intelligence, 14(3), 507-543. https://doi.org/10.1142/S0218213005002235

McCloskey, J. T., Lilieholm, R. J., Boone, R., Reid, R., Sader, S., Nkedianye, D.,Said, M. \& Worden, J. (2011). A participatory approach for modeling alternative future land use scenarios around Nairobi National Park using Bayesian Belief Networks. WIT Transactions on Ecology and the Environment, 144, 43-57. https://doi.org/10.2495/ECO110041

Montgomery, J. (1998). Making a city: urbanity, vitality and urban design. Journal of Urban Design, 3(1), 93-116.

Shannon, C. E. (1948). A mathematical theory of communication. Bell System Technology Journal, 27, 379-423, 623-656.

Simpson, E. H. (1949). Measurement of diversity. Nature, 163, 688.

Tan, W., \& Klaasen, I. (2007, September 12-14). 24/7 environments: A theoretical and empirical exploration from an urban planners perspective [Paper presentation]. European Urban Research Association (EURA), Glasgow, Scotland.

Turgut, S., Özden, P. (2005). Sürdürülebilir ve turizm eksenli bir kentsel dönüşüm hedefine doğru: Eminönü tarihi kent merkezi [Towards an urban transformation target focused on sustainable and tourism: Eminönü historical city center]. Planlama, 2005 (1).

United Nations Educational, Scientific and Cultural Organization (UNESCO) World Heritage Center. (2006). Historic areas of Istanbul (Expert Mission Report: C 356). https://whc.unesco.org/archive/2006/mis356-2006.pdf

United Nations Educational, Scientific and Cultural Organization (UNESCO) Turkey National Commission. (2009). World heritage sites Turkey, the current state in protection and management. Retrieved July 21, 2021, from http://whc.unesco.org/en/list/356

Wood, S. A., Guerry, A. D., Silver, J. M., \& Lacayo, M. (2013). Using social media to quantify nature-based tourism and recreation. Scientific Reports, 3(2976), 1-7. https://doi.org/10.1038/srep02976 
Yanık, S. Aktas, E. Topcu, İ. Y. (2017). Traveler satisfaction in rapid rail systems: The case of Istanbul Metro. International Journal of Sustainable Transportation, 11(9), 642-658. https://doi.org/10.1080/15568318.2012.674627 